\title{
Perpendicular magnetic anisotropy of full-Heusler films in $\mathrm{Pt} / \mathrm{Co}_{2} \mathrm{FeAl} / \mathrm{MgO}$ trilayers
}

Xiaoqi Li, Shaoqian Yin, Yupeng Liu, Delin Zhang, Xiaoguang Xu *, Jun Miao, and Yong Jiang *

State Key Laboratory for Advanced Metals and Materials, School of Materials Science and Engineering, University of Science and Technology Beijing, Beijing 100083, China.

We report on perpendicular magnetic anisotropy (PMA) in a $\mathrm{Pt} / \mathrm{Co}_{2} \mathrm{FeAl} / \mathrm{MgO}$ sandwiched structure with a thick $\mathrm{Co}_{2} \mathrm{FeAl}$ layer of 2-2.5 $\mathrm{nm}$. The PMA is thermally stable that the anisotropy energy density $\mathrm{K}_{\mathrm{u}}$ is $1.3 \times 10^{6} \mathrm{erg} / \mathrm{cm}^{3}$ for the structure with 2 $\mathrm{nm} \mathrm{Co}_{2} \mathrm{FeAl}$ after annealing at $350{ }^{\circ} \mathrm{C}$. The thicknesses of $\mathrm{Co}_{2} \mathrm{FeAl}$ and $\mathrm{MgO}$ layers greatly affect the PMA. Our results provide an effective way to realize relative thick perpendicularly magnetized Heusler alloy films.

* Email: xgxu@ustb.edu.cn, yjiang@ustb.edu.cn 
Magnetic tunnel junctions (MTJs) as core elements of magnetic random access memory (MRAM) have gotten aroused enormous interests for their large magnetoresistance (MR). Because the large MR comes from spin-polarized tunneling, ${ }^{1,2}$ spin polarization at Fermi level $\left(\mathrm{E}_{\mathrm{F}}\right)$ of the two ferromagnetic $(\mathrm{FM})$ electrodes in MTJs is a key factor to determine MR based on Julliere's model. ${ }^{3}$ Therefore half-metals, which have $100 \%$ theoretical spin polarization, are ideal electrodes for MTJs. ${ }^{4-6}$

A prediction shows that FM electrodes with perpendicular magnetic anisotropy (PMA) could bring faster and smaller MTJs than those with in-plane magnetic anisotropy. ${ }^{7}$ However till now no traditional PMA film can satisfy the requirements of high thermal stability at reduced dimension, low critical current for spin-torque-induced switching and high MR simultaneously. ${ }^{8,9}$ Recently, Pt (or $\mathrm{Pd}) / \mathrm{Co}$ (or $\mathrm{CoFeB}) / \mathrm{MO}_{\mathrm{x}}(\mathrm{M}=\mathrm{Mg}$ and $\mathrm{Al}$, etc.) trilayers with strong PMA were reported. ${ }^{10-15}$ The PMA was supposed to origin from the hybridization of Co $3 \mathrm{~d}$ and O $2 p$ orbitals. A high MR ratio of $120 \%$ was also obtained in perpendicular $\mathrm{CoFeB} / \mathrm{MgO} / \mathrm{CoFeB}$ MTJ. ${ }^{9}$ Due to the high spin polarization, it should be a big breakthrough if one can realize half metals with PMA. Perpendicularly magnetized $\mathrm{Pt} / \mathrm{Co}_{2} \mathrm{FeAl}$ has really been fabricated. ${ }^{16}$ However the thin thickness of $0.6 \mathrm{~nm}$ may cause the deterioration of spin polarization and thermal stability for $\mathrm{Co}_{2} \mathrm{FeAl}$ films. In this letter, we report thick $\mathrm{Co}_{2} \mathrm{FeAl}$ films of 2-2.5 nm with $\mathrm{PMA}$ in $\mathrm{Pt} / \mathrm{Co}_{2} \mathrm{FeAl} / \mathrm{MgO}$ trilayers. The perpendicular $\mathrm{Co}_{2} \mathrm{FeAl}$ films show good thermal stability after $350{ }^{\circ} \mathrm{C}$ annealing. 
All the thin films were deposited on $\mathrm{Si} / \mathrm{SiO}_{2}$ substrates with a buffer Ta layer of 3 $\mathrm{nm}$ by magnetron sputtering. The stack structure is $\mathrm{Si} / \mathrm{SiO}_{2} / \mathrm{Ta}(3) / \mathrm{Pt}(20) / \mathrm{Co}_{2} \mathrm{FeAl}$ $\left(t_{\mathrm{CFA}}\right) / \mathrm{MgO}\left(\mathrm{t}_{\mathrm{MgO}}\right)$, (layer thickness in nanometer, $t_{\mathrm{CFA}}$ and $\mathrm{t}_{\mathrm{MgO}}$ represent the thicknesses of $\mathrm{Co}_{2} \mathrm{FeAl}$ and $\mathrm{MgO}$, respectively). The base pressure of the sputtering system was better than $9.0 \times 10^{-6} \mathrm{~Pa}$. The annealing process was carried out in a vacuum chamber under $2 \times 10^{-4} \mathrm{~Pa}$ for 0.5 hour in the absence of magnetic field. The thin films were then characterized by alternating gradient magnetometer (AGM), magnetic force microscopy (MFM), and X-ray photoelectron spectroscopy (XPS), respectively.

Figure 1 shows the M-H loops for the as-deposited and annealed samples with $\mathrm{t}_{\mathrm{CFA}}=2 \mathrm{~nm}$ and $\mathrm{t}_{\mathrm{MgO}}=0.5 \mathrm{~nm}$. No apparent PMA is observed for the as-deposited film. After annealing at $150{ }^{\circ} \mathrm{C}$, the PMA is clearly realized. It is similar to $\mathrm{Pd}$ (or $\mathrm{Pt}) / \mathrm{CoFeB}$ (or $\mathrm{Co}$ ) $/ \mathrm{MgO}$ structure in which there is also a transition from in-plane magnetic anisotropy to PMA after annealing, which was due to the oxidation of $\mathrm{CoFeB}$ (or $\mathrm{Co}) .{ }^{14,15}$ For our samples, while the annealing temperature $\left(\mathrm{T}_{\mathrm{an}}\right)$ is as high as $350{ }^{\circ} \mathrm{C}$, the PMA is stably maintained and the anisotropy energy density $\mathrm{K}_{\mathrm{u}}$ is estimated to be about $1.3 \times 10^{6} \mathrm{erg} / \mathrm{cm}^{3}$ by using the equation $\mathrm{K}_{\mathrm{u}}=\mathrm{M}_{\mathrm{s}} \mathrm{H}_{\mathrm{an}} / 2$, where $\mathrm{M}_{\mathrm{s}}$ and $\mathrm{H}_{\mathrm{an}}$ refer to saturation magnetization and anisotropy field, respectively. Therefore the PMA in the structure has a good thermal stability.

The perpendicular coercivity $\left(\mathrm{H}_{\mathrm{c}}\right)$ and saturation field $\left(\mathrm{H}_{\mathrm{s}}\right)$ as functions of $\mathrm{T}_{\text {an }}$ are plotted in Figure 2. $\mathrm{H}_{\mathrm{s}}$ decreases sharply from 6000 Oe for the as-deposited sample down to 350 Oe for the $150{ }^{\circ} \mathrm{C}$ annealed one. At the same time, $\mathrm{H}_{\mathrm{c}}$ increases from 18 
to 40 Oe. When $\mathrm{T}_{\text {an }}$ further increases up to $350{ }^{\circ} \mathrm{C}, \mathrm{H}_{\mathrm{s}}$ only has a slight change and $\mathrm{H}_{\mathrm{c}}$ reaches a maximum value (60 Oe). The inset of Fig. 2 shows the MFM image of the sample annealed at $350{ }^{\circ} \mathrm{C}$. The regularly spaced stripe domains further justify the existence of PMA. When the sample is annealed at $400{ }^{\circ} \mathrm{C}, \mathrm{H}_{\mathrm{s}}$ increases to 7600 Oe. The PMA disappears. So the annealing process plays a crucial role for the PMA, which is different from $\mathrm{Pt} / \mathrm{Co}_{2} \mathrm{FeAl}$ multilayers. ${ }^{16}$

Because one possible origin of the PMA is the hybridization of Co $3 d$ and O $2 p$ orbitals, ${ }^{12}$ XPS is performed for the sample of $\mathrm{Pt}(20) / \mathrm{Co}_{2} \mathrm{FeAl}(2) / \mathrm{MgO}(0.5)$ annealed at $350{ }^{\circ} \mathrm{C}$ to obtain any information on the composition of $\mathrm{Co}$ and $\mathrm{Fe}$. The $\mathrm{Co}$ and $\mathrm{Fe} 2 \mathrm{p}$ spectra are shown in Figure 3. The main peaks of $\mathrm{CoO} 2 \mathrm{p}_{3 / 2}, \mathrm{CoO} 2 \mathrm{p}_{1 / 2}$ for Co $2 p$ and $\mathrm{Fe}_{2} \mathrm{O}_{3} 2 \mathrm{p}_{3 / 2}, \mathrm{Fe}_{2} \mathrm{O}_{3} 2 \mathrm{p}_{1 / 2}$ for $\mathrm{Fe} 2 \mathrm{p}$ have been detected, demonstrating that the $\mathrm{Co}_{2} \mathrm{FeAl}$ film is partially oxidized. As a result, $\mathrm{Co}-\mathrm{O}$ and $\mathrm{Fe}-\mathrm{O}$ bonds are coexisting. Besides, two satellite peaks of Co $2 p$ (marked as ' $\mathrm{S}$ ') can be distinguished which arise from the charge transfer between Co $3 \mathrm{~d}$ and O $2 \mathrm{p} .{ }^{17-19}$ There is a similar behavior between $\mathrm{Fe} 3 \mathrm{~d}$ and $\mathrm{O} 2 \mathrm{p}$. The charge transfer at the $\mathrm{Co}_{2} \mathrm{FeAl} / \mathrm{MgO}$ interface may create a strong band splitting and lead to the PMA. ${ }^{12}$

Figure 4 shows $\mathrm{M}_{\mathrm{s}}$ and the effective thickness of $\mathrm{Co}_{2} \mathrm{FeAl}\left(\mathrm{t}_{\text {eff }}\right)$ as a function of $\mathrm{t}_{\mathrm{MgO}}$ for the as-deposited $\mathrm{Pt}(20) / \mathrm{Co}_{2} \mathrm{FeAl}(2) / \mathrm{MgO}\left(\mathrm{t}_{\mathrm{MgO}}\right)$ samples. The values of $\mathrm{t}_{\mathrm{eff}}$ are estimated by comparing $\mathrm{M}_{\mathrm{s}}$ of each sample with that of the $\mathrm{Pt}(5) / \mathrm{Co}_{2} \mathrm{FeAl}(2) / \mathrm{Pt}$ (4). It is unexpected that $\mathrm{M}_{\mathrm{s}}$ monotonously decreases with the increasing $t_{\mathrm{MgO}}$. The strong dependence of $\mathrm{M}_{\mathrm{s}}$ on the thickness of oxide layer has not ever been mentioned in $\mathrm{Pt} / \mathrm{Co}$ (or $\mathrm{CoFeB}$ ) $/ \mathrm{MO}_{\mathrm{x}}$ systems, ${ }^{12-15}$ and is due to different degree of oxidation at 
the $\mathrm{Co}_{2} \mathrm{FeAl} / \mathrm{MgO}$ interface. It is reasonably assumed that the thicker sputtered $\mathrm{MgO}$ film leads to a deeper oxidation at the interface. There is also an optimum degree of oxidation leading to PMA in the $\mathrm{Pt} / \mathrm{Co}_{2} \mathrm{FeAl} / \mathrm{MgO}$ structure, which is similar to $\mathrm{Pt} / \mathrm{Co} / \mathrm{MO}_{\mathrm{x}}$ trilayers. ${ }^{12} \mathrm{t}_{\mathrm{eff}}$ is $1.3 \mathrm{~nm}$ in the as-deposited state for the sample with $\mathrm{t}_{\mathrm{CFA}}=2 \mathrm{~nm}$ and $\mathrm{t}_{\mathrm{MgO}}=0.5 \mathrm{~nm}$. After annealing at $150{ }^{\circ} \mathrm{C}, \mathrm{t}_{\mathrm{eff}}$ decreases to $1.1 \mathrm{~nm}$ and the sample shows PMA. On the other hand, the Pt (5)/ $\mathrm{Co}_{2} \mathrm{FeAl}(2) / \mathrm{Pt}$ (4) sample keeps in-plane anisotropy in both as-deposited and annealed states. Therefore the oxidation at the $\mathrm{Co}_{2} \mathrm{FeAl} / \mathrm{MgO}$ interface plays a crucial role in the PMA.

While $\mathrm{t}_{\mathrm{CFA}}=2.5 \mathrm{~nm}$ and $\mathrm{t}_{\mathrm{MgO}}=0.5 \mathrm{~nm}$, we have also deposited samples with the structure of $\mathrm{Pt}(20) / \mathrm{Co}_{2} \mathrm{FeAl}(2.5) / \mathrm{MgO}(0.5)$. The as-deposited sample is in-plane magnetized, as shown in the inset of Fig. 5. After annealing at $250{ }^{\circ} \mathrm{C}$, the sample becomes PMA as shown in Fig. 5. The PMA is maintained after $350{ }^{\circ} \mathrm{C}$ annealing, as in the inset of Fig. 6. Fig. 6 plots the variation of the perpendicular $H_{s}$ for the samples $\mathrm{Pt}(20) / \mathrm{Co}_{2} \mathrm{FeAl}\left(\mathrm{t}_{\mathrm{CFA}}\right) / \mathrm{MgO}(0.5)$ with different $\mathrm{t}_{\mathrm{CFA}}$ in both as-deposited and $350{ }^{\circ} \mathrm{C}$ annealed states, respectively. All the samples annealed at $350{ }^{\circ} \mathrm{C}$ have lower $\mathrm{H}_{\mathrm{S}}$ compared with the as-deposited state because more $\mathrm{Co}-\mathrm{O}$ and $\mathrm{Fe}-\mathrm{O}$ bonds are created to enhance the PMA after annealing. Large $\mathrm{H}_{\mathrm{s}}$ values of the samples with $\mathrm{t}_{\mathrm{CFA}}<2 \mathrm{~nm}$ demonstrate their in-plane anisotropy. It may be due to the excessive oxidation leading to a too small $t_{\text {eff. }}$ The minimum value of $\mathrm{H}_{\mathrm{s}}$ apears in the $350{ }^{\circ} \mathrm{C}$ annealed sample with $\mathrm{t}_{\mathrm{CFA}}=2 \mathrm{~nm}$.

In conclusion, the PMA is observed in the trilayers $\mathrm{Pt} / \mathrm{Co}_{2} \mathrm{FeAl} / \mathrm{MgO}$ while the thicknesses of the $\mathrm{Co}_{2} \mathrm{FeAl}$ film are 2 and $2.5 \mathrm{~nm}$. The PMA can be stablely 
maintained after $350{ }^{\circ} \mathrm{C}$ annealing. A possible origin of the PMA is the Co-O and Fe-O bands hybridization. Therefore we suppose that all Co-based Heusler alloy films with PMA can be realized in the structure of $\mathrm{Pt} /$ Heusler alloy/MgO.

\section{Acknowledgements}

This work was partially supported by the NSFC (Grant Nos. 50831002, 50971025, 51071022), the Keygrant Project of Chinese Ministry of Education (No. 309006) and the National Basic Research Program of China (Grant No. 2007CB936202). 


\section{References}

[1] J. S. Moodera, L. R. Kinder, T. M. Wong, and R. Meservey: Phys. Rev. Lett. 74 (1995) 3273.

[2] T. Miyazaki, and N. Tezuka: J. Magn. Magn. Mater. 139 (1995) L231.

[3] M. Julliere: Phys. Lett. A 54 (1975) 225.

[4] W. Wang, H. Sukegawa, R. Shan, S. Mitani, and K. Inomata: Appl. Phys. Lett. 86 (2005) 232503.

[5] S. Okamura, A. Miyazaki, S. Sugimoto, N. Tezuka, and K. Inomata: Appl. Phys. Lett. 86 (2005) 232503

[6] T. Marukame, T. Ishikawa, S. Hakamata, K. Matsuda, T. Uemura, and M.Yamamoto: Appl. Phys. Lett. 90 (2007) 012508.

[7] Y. F. Ding, J. H. Judy, and J. P. Wang: J. Appl. Phys. 97 (2005) $10 J 117$.

[8] Q. L. Lv, J. W. Cai, H. Y. Pan, and B. S. Han: Appl. Phys. Exp. 3 (2010) 093003.

[9] S. Ikeda, K. Miura, H. Yamamoto, K. Mizunuma, H. D. Gan, M. Endo, S. Kanai, J. Hayakawa, F. Matsukura, and H. Ohno: Nat. Mater. 9 (2010) 721.

[10] S. Monso, B. Rodmacq, S. Auffret, G. Casali, F. Fettar, B. Gilles, B. Dieny, and P. Boyer: Appl. Phys. Lett. 80 (2002) 4157.

[11] B. Rodmacq, S. Auffret, B. Dieny, S. Monso, and P. Boyer: J. Appl. Phys. 93 (2003) 7513.

[12] A. Manchon, C. Ducruet, L. Lombard, S. Auffret, B. Rodmacq, B. Dieny, S. Pizzini, J. Vogel, V. Uhlíŕ, M. Hochstrasser, and G. Panaccione: J. Appl. Phys. 104 (2008) 043914.

[13] Y. Dahmane, S. Auffret, U. Ebels, B. Rodmacq, and B. Dieny: IEEE Trans. Magn. 45 (2008) 3472.

[14] L. E. Nistor, B. Rodmacq, S. Auffret, and B. Dieny: Appl. Phys. Lett. 94 (2009) 012512. 
[15] J. H. Jung, S. H. Lim, and S. R. Lee: Appl. Phys. Lett. 96 (2010) 042503.

[16] W. Wang, H. Sukegawa, and K. Inomata: Appl. Phys. Express 3 (2010) 093002.

[17] E. Y. Tsymbal, K. D. Belashchenko, J. P. Velev, S. S. Jaswal, M. van Schilfgaarde, I. I. Oleynik, and D. A. Stewart: Prog. Mater. Sci. 52 (2007) 401.

[18] I. I. Oleinik, E. Yu. Tsymbal, and D. G. Pettifor: Phys. Rev. B 62 (2000) 3952.

[19] K. D. Belashchenko, E. Y. Tsymbal, I. I. Oleinik, and M. van Schilfgaarde: Phys. Rev. B 71 (2005) 224422. 


\section{Figure captions}

Fig. 1. M-H loops for the sample Pt (20)/ $\mathrm{Co}_{2} \mathrm{FeAl}(2) / \mathrm{MgO}(0.5)$ after annealing at different temperatures $\left(\mathrm{T}_{\mathrm{an}}\right)$.

Fig. 2. The perpendicular $\mathrm{H}_{\mathrm{c}}$ and $\mathrm{H}_{\mathrm{s}}$ as functions of $\mathrm{T}_{\mathrm{an}}$ for the sample $\mathrm{Pt}(20) / \mathrm{Co}_{2} \mathrm{FeAl}$ (2)/MgO (0.5). The inset shows the MFM image of the $350{ }^{\circ} \mathrm{C}$ annealed sample.

Fig. 3. Co and Fe 2p XPS spectra for the sample of Pt (20)/ $\mathrm{Co}_{2} \mathrm{FeAl}(2) / \mathrm{MgO}(0.5)$ annealed at $350{ }^{\circ} \mathrm{C}$.

Fig. 4. $\mathrm{M}_{\mathrm{s}}$ and the effective thickness of $\mathrm{Co}_{2} \mathrm{FeAl}$ (teff) as a function of $\mathrm{t}_{\mathrm{MgO}}$ for the as-deposited $\mathrm{Pt}(20) / \mathrm{Co}_{2} \mathrm{FeAl}(2) / \mathrm{MgO}\left(\mathrm{t}_{\mathrm{MgO}}\right)$ samples. Inset: Perpendicular M-H loop for the as-deposited $\mathrm{Pt}(5) / \mathrm{Co}_{2} \mathrm{FeAl}(2) / \mathrm{Pt}(4)$ structure.

Fig. 5. Perpendicular M-H loop for the $250{ }^{\circ} \mathrm{C}$ annealed sample of $\mathrm{Pt}(20) / \mathrm{Co}_{2} \mathrm{FeAl}$ (2.5)/MgO (0.5). The inset shows $\mathrm{M}-\mathrm{H}$ loops for the as-deposited sample.

Fig. 6. Variations of the perpendicular $\mathrm{H}_{\mathrm{s}}$ with $\mathrm{t}_{\mathrm{CFA}}$ for the samples of $\mathrm{Pt}(20) / \mathrm{Co}_{2} \mathrm{FeAl}$ $\left(\mathrm{t}_{\mathrm{CFA}}\right) / \mathrm{MgO}(0.5)$ in the as-deposited and $350{ }^{\circ} \mathrm{C}$ annealed states, respectively. The inset shows $\mathrm{M}-\mathrm{H}$ loops for the $350{ }^{\circ} \mathrm{C}$ annealed sample with $\mathrm{t}_{\mathrm{CFA}}=2.5 \mathrm{~nm}$. 
Fig. 1 (X.Q.Li et al.):

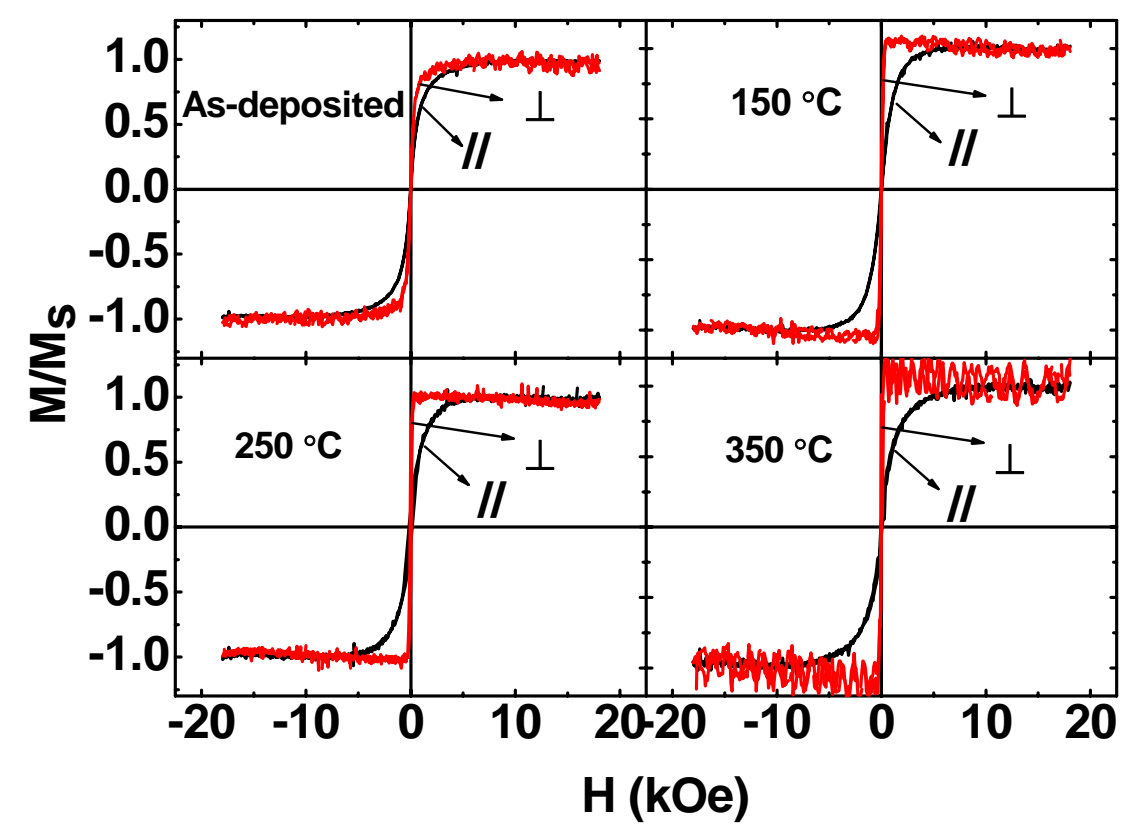


Fig. 2 (X.Q.Li et al.):

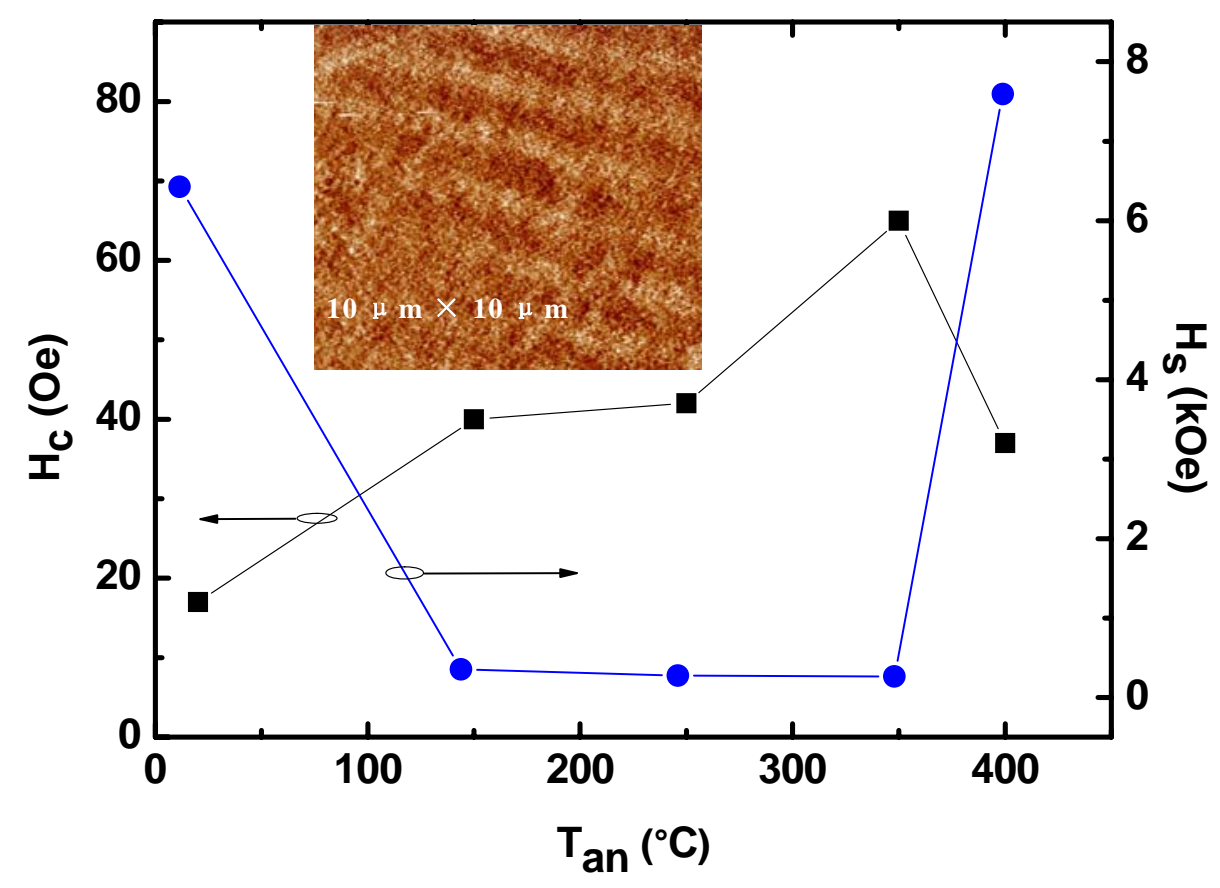


Fig. 3 (X.Q.Li et al.):

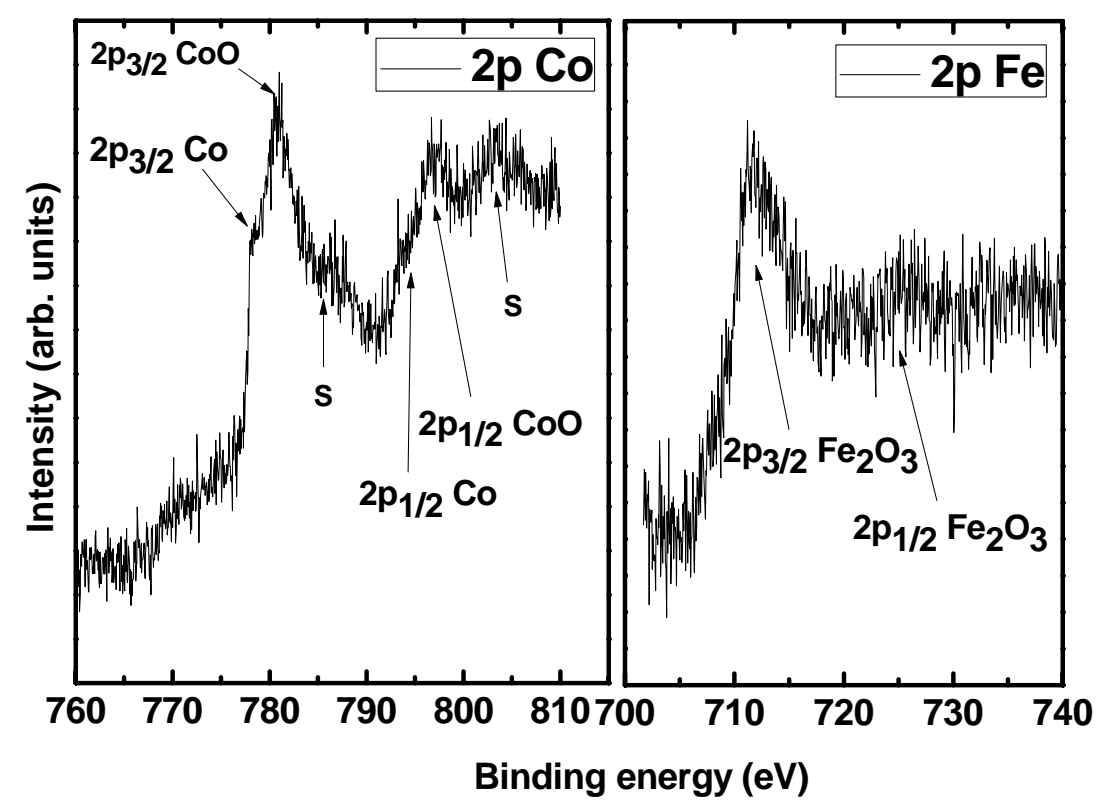


Fig. 4 (X.Q.Li et al.):

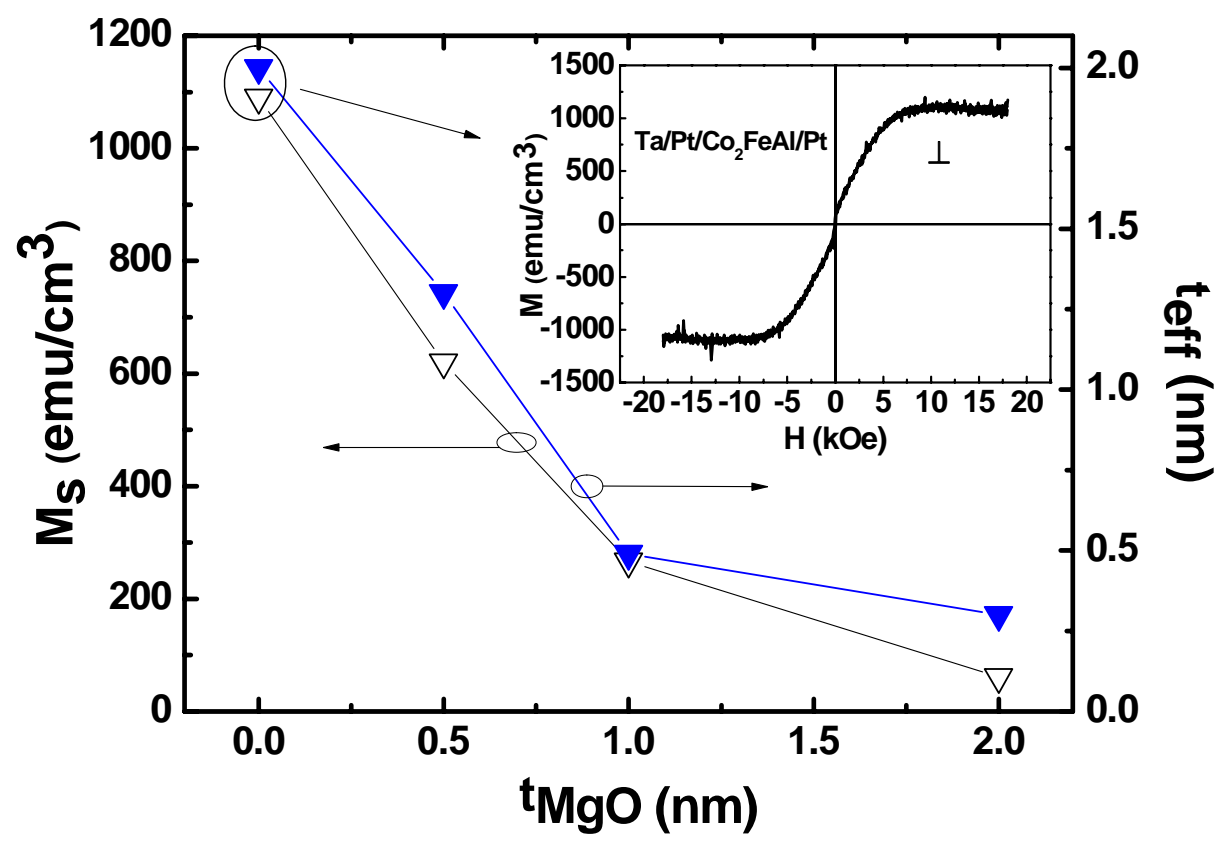


Fig. 5 (X.Q.Li et al.):

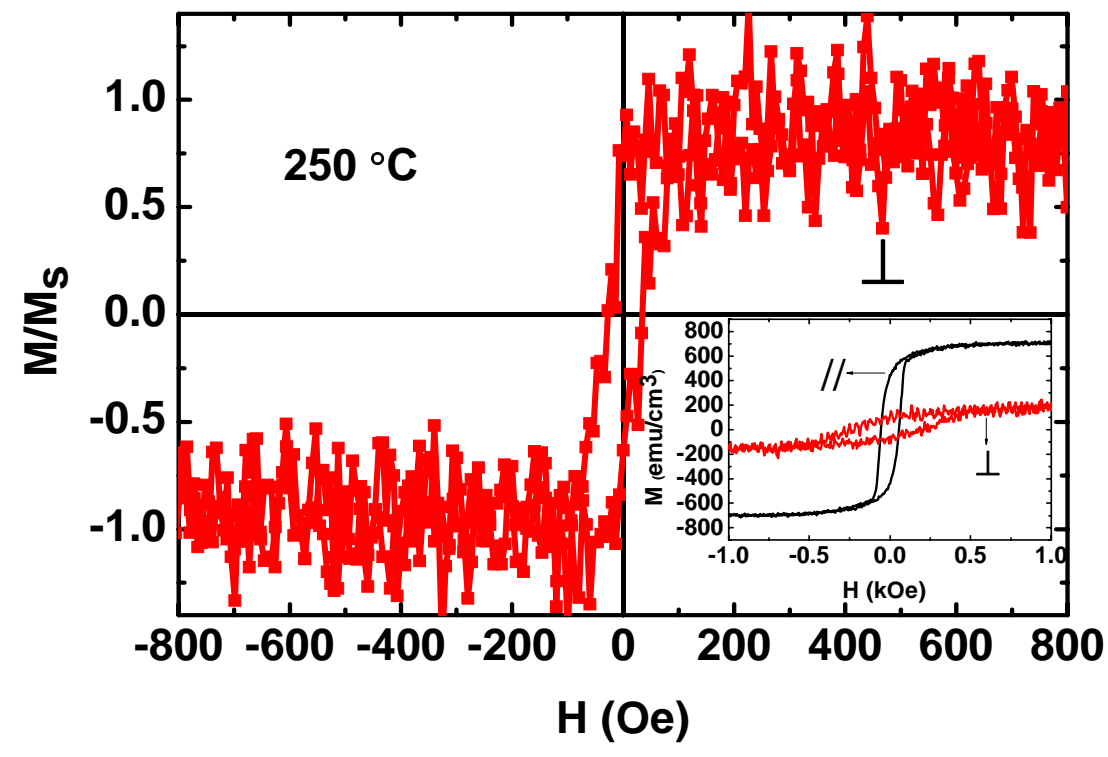


Fig. 6 (X.Q.Li et al.):

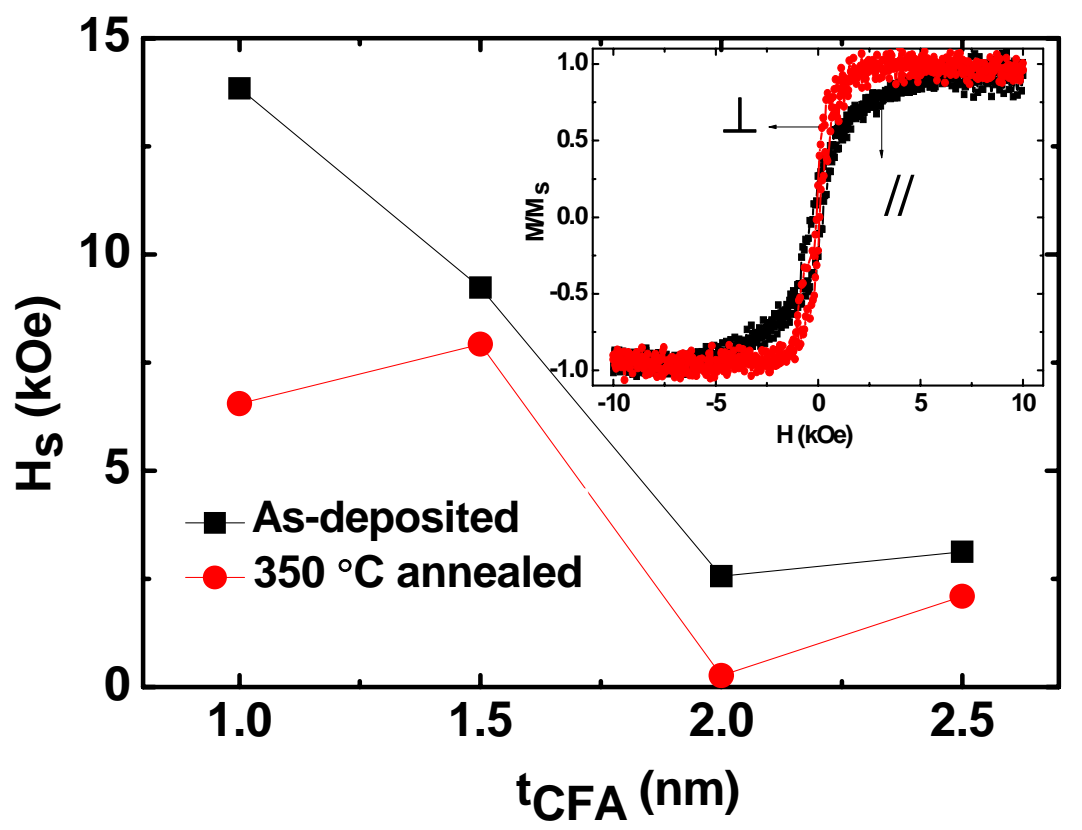

